Article

\title{
Spatio-Temporal Analysis and Uncertainty of Fractional Vegetation Cover Change over Northern China during 2001-2012 Based on Multiple Vegetation Data Sets
}

\author{
Linqing Yang ${ }^{1,2}(\mathbb{D})$, Kun Jia ${ }^{1,2, *}(\mathbb{D})$, Shunlin Liang ${ }^{3}$, Meng Liu ${ }^{4,5}$, Xiangqin Wei ${ }^{6}$ (D), \\ Yunjun Yao ${ }^{1,2} \mathbb{B D}$, Xiaotong Zhang ${ }^{1,2}$ and Duanyang Liu ${ }^{1,2}$ \\ 1 State Key Laboratory of Remote Sensing Science, Faculty of Geographical Science, Beijing Normal \\ University, Beijing 100875, China; linqingyang@mail.bnu.edu.cn (L.Y.); boyyunjun@163.com (Y.Y.); \\ xtngzhang@bnu.edu.cn (X.Z.); 201721170045@mail.bnu.edu.cn (D.L.) \\ 2 Beijing Engineering Research Center for Global Land Remote Sensing Products, \\ Faculty of Geographical Science, Beijing Normal University, Beijing 100875, China \\ 3 Department of Geographical Sciences, University of Maryland, College Park, MD 20742, USA; \\ sliang@bnu.edu.cn \\ 4 State Key Laboratory of Earth Surface Processes and Resource Ecology, Beijing Normal University, \\ Beijing 100875, China; mengliu@mail.bnu.edu.cn \\ 5 College of Global Change and Earth System Science, Beijing Normal University, Beijing 100875, China \\ 6 Institute of Remote Sensing and Digital Earth, Chinese Academy of Sciences, Beijing 100101, China; \\ weixq@radi.ac.cn \\ * Correspondence: jiakun@bnu.edu.cn; Tel.: +86-10-5880-0152
}

Received: 7 January 2018; Accepted: 2 April 2018; Published: 3 April 2018

\begin{abstract}
Northern China is one of the most sensitive and vulnerable regions in the country. To combat environmental degradation in northern China, a series of vegetation protection programs, such as the Three-North Shelter Forest Program (TNFSP), have been implemented. Whether the implementation of these programs in northern China has improved the vegetation conditions has merited global attention. Therefore, quantifying vegetation changes in northern China is essential for meteorological, hydrological, ecological, and societal implications. Fractional vegetation cover (FVC) is a crucial biophysical parameter which describes land surface vegetation conditions. In this study, four FVC data sets derived from remote sensing data over northern China are employed for a spatio-temporal analysis to determine the uncertainty of fractional vegetation cover change from 2001 to 2012. Trend analysis of these data sets (including an annually varying estimate of error) reveals that FVC has increased at the rate of $0.26 \pm 0.13 \%, 0.30 \pm 0.25 \%, 0.12 \pm 0.03 \%, 0.49 \pm 0.21 \%$ per year in northern China, Northeast China, Northwest China, and North China during the period 2001-2012, respectively. In all of northern China, only $33.03 \%$ of pixels showed a significant increase in vegetation cover whereas approximately $16.81 \%$ of pixels showed a significant decrease and $50.16 \%$ remained relatively stable.
\end{abstract}

Keywords: fractional vegetation cover (FVC); multi-data set; northern China; spatio-temporal; inter-annual variation; uncertainty; standard error of the mean

\section{Introduction}

Northern China has typical characteristics of fragile ecological situations and is one of the most sensitive and vulnerable regions in China. For historical reasons, farming practices, grazing and other reasons, northern China is suffering long-term land degeneration, a lack of fresh water, drought, 
and other extreme weather, etc. [1-4]. Therefore, northern China is a key area deserving of scholarly attention. Faced with these problems, the Chinese government has realized the seriousness of the situations and has implemented a series of policy measures to ease the environmental crisis.

Vegetation, which is bonded soil, climatic, hydrologic, and other elements in the whole ecosystem, is a sensitive indicator of climate change and human activities and thus influences climate by affecting the energy, water, and carbon cycle [5-7]. Vegetation is also a positive factor in the prevention of soil and water loss as well as in the control of sandstorms; it also is an important factor for soil erosion prediction. Vegetation absorbs $\mathrm{CO}_{2}$ through photosynthesis from the atmosphere to mitigate global warming. Meanwhile, vegetation can increase precipitation, runoff regulation, reduce flood and drought, reduce pollution, and improve the ecological environment. Vegetation change can also affect the energy balance as well as biochemical and biophysical processes [8].

Therefore, many ecological engineering programs have been implemented in northern China to improve the regional ecological environment $[5,9]$ such as the Three-North Shelterbelt Forest Program (TNSFP), the Green to Grain Program (GTGP), and the Natural Forest Conservation Program (NFCP) [10-13]. In these ecological programs, TNFSP is the oldest, invested in the most, and affected the widest range. The TNSFP was officially launched in 1979 and involves 13 provinces, autonomous regions, and municipalities in the Three-North region with a total planned area of more than 4 million $\mathrm{km}^{2}$, i.e., nearly $42 \%$ of the total area of China. To date, a total of 30.6 million ha of afforestation has been carried out at a total cost of $¥ 4$ billion $[1,6]$. Because of its huge geographic extent and complexity, the project will extend to 2050 and will provide important information through the monitoring of its long-term progress [14]. The main purpose of such projects is to prevent land desertification, control sandstorms, and improve both local water resources and the natural environment. Whether the implementation of these programs throughout northern China has improved the vegetation conditions has merited global attention.

Therefore, quantifying vegetation changes in northern China is essential. Fractional Vegetation Cover (FVC), which is an important variable describing land surface vegetation, is generally defined as the fraction of green vegetation as seen from the nadir of the statistical area. FVC is also a crucial biophysical parameter for studying the atmosphere, pedosphere, hydrosphere, and biosphere as well as their interactions [15-18]. Reliable information on FVC change over northern China is needed for environment and ecological monitoring, environmental assessment, and the evaluation of vegetation change feedbacks in climate. For example, Su et al. [19] used MODIS data to detect vegetation changes in the agricultural-pastoral areas of northern China from 2001 to 2013. Liu et al. [20] used SPOT-VGT data from 1998 to 2007 to detect vegetation change throughout northern China. Zhang et al. [21] analyzed the spatio-temporal vegetation changes of northern China from 2000 to 2012. Li et al. [22] analyzed the spatial-temporal pattern and change of FVC in northern China during 2001-2012. Li et al. [23] conducted a comparison of multiple forest cover data sets to monitor forest cover changes across China.

However, most of the studies used a single data set in which may exist large uncertainties. The accuracy of the FVC data set is unclear in northern China resulting from a lack of ground measurements. As a result, its attributions and any response to climate change generated from a single source may lead to large uncertainties. A multi-data set approach to analyze the vegetation change is a logical response to the challenges mentioned above as it fuses the strengths of the various platforms and methodologies as well as provides an estimate of the uncertainty. Therefore, the main object of this study is to develop a multi-data set estimate of FVC change throughout northern China for the period of 2001-2012. It is also expected to provide reliable and accurate information for regional sustainable development, ecological restoration project planning, and ecological environmental protection. 


\section{Data and Methods}

\subsection{Study Area}

The study area (Figure 1), based on provincial boundaries, contains 13 provinces, cities, autonomous regions, and municipalities in northern China. Reflecting on the diversity of the natural environment, northern China has been further subdivided into northeastern China, northwestern China, and northern China when conducting statistical analysis at a regional scale.

Northeast China contains Heilongjiang, Liaoning, Jilin province as well as the eastern part of the Inner Mongolia Autonomous Region. Northeast China is characterized by temperate monsoon climate with a low mean annual temperature $\left(5.2^{\circ} \mathrm{C}\right)$ and annual precipitation reaching 300 1000 mm. Northeast China contains almost all major forest types in northern Eastern Asia which include cold-temperate conifer mixed forests, temperate conifer forests, broadleaf mixed forests, and warm-temperate deciduous broadleaf mixed forests and covers the largest area of natural forest in China [24].

North China contains Beijing, Tianjin, Hebei, Shandong, Shanxi, Shaanxi as well as the middle part of the Inner Mongolia Autonomous Region. North China is defined by plains and a warm sub-humid continental climate and has a large annual range of temperature; the annual precipitation reaches 400-800 mm, mainly in the summer.

Northwest China contains the western part of the Inner Mongolia Autonomous Region, the Xinjiang Uygur autonomous region, the Ningxia Hui autonomous region, along with Gansu province. The climate of Northwest China varies and includes a temperate continental monsoon climate, arid and semi-arid climates, and a warm temperate continental arid climate. It is distinguished by a low annual mean temperature, a large annual range of temperature, and low precipitation (50-200 mm/year). It has the biggest desert in China, the Taklimakan desert, and the main vegetation type is grassland, shrubland, etc.

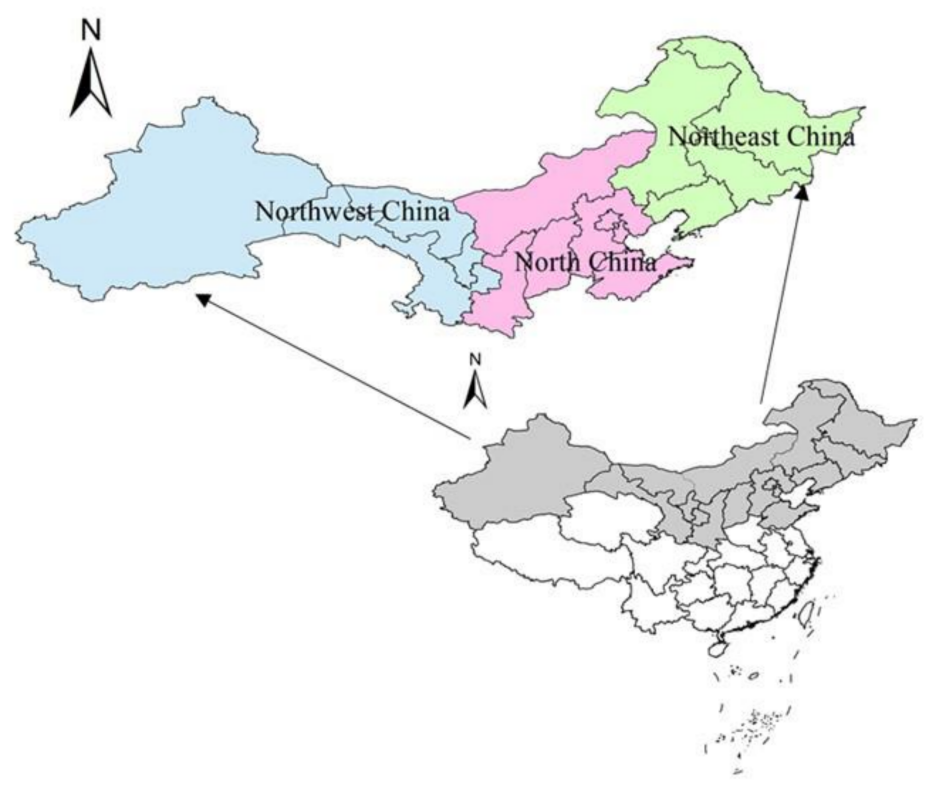

Figure 1. Location of the research area (The green area represents northeast China, the pink area for North China, the blue area for Northwest China, respectively).

\subsection{Data Sets}

Four FVC data sets were used to estimate vegetation change over northern China in this study, including the Global LAnd Surface Satellite (GLASS) FVC product, GEOV1 FVC product, TRAGL FVC product, and Li product, which are summarized in Table 1. 
Table 1. The summary of fractional vegetation cover (FVC) data sets used in the analysis.

\begin{tabular}{ccccccc}
\hline Product Name & Sensor & Available Time & $\begin{array}{c}\text { Temporal } \\
\text { Resolution }\end{array}$ & $\begin{array}{c}\text { Spatial } \\
\text { Coverage }\end{array}$ & $\begin{array}{c}\text { Spatial } \\
\text { Resolution }\end{array}$ & Reference \\
\hline GLASS-MODIS & MODIS & $2001-$ now & 8 days & Global & $500 \mathrm{~m}$ & {$[16]$} \\
GEOV1 & SPOT VGT & $2001-$ now & 10 days & Global & $1 \mathrm{~km}$ & {$[25]$} \\
TRAGL & MOIDS & $2001-2012$ & 8 days & Global & $1 \mathrm{~km}$ & {$[26]$} \\
Li & MODIS & $2001-2012$ & 8 days & Northern China & $0.011^{\circ}$ & {$[16]$} \\
\hline
\end{tabular}

\subsubsection{GLASS MODIS-FVC Product}

The GLASS FVC product [16] is one of the new products in the GLASS product suite, which is supported by China's National High Technology Research and Development Program to generate long-term global land surface parameters. The GLASS MODIS-FVC product is generated using the generalized regression neural networks (GRNNs) with training data derived from MODIS Version 5 surface reflectance data (MOD09A1) and FVC values obtained from Landsat data using the dimidiate pixel model. The temporal and spatial resolution of GLASS MODIS-FVC are 8-day and $0.5 \mathrm{~km}$ with a sinusoidal grid projection, respectively. Jia et al. compared the GLASS FVC with GEOV1 FVC which was the best global FVC product and results indicated GLASS FVC presented a much better spatial and temporal continuity and marginally better accuracy with over 44 validation of land European remote sensing instruments (VALERI) validation sites.

\subsubsection{GEOV1 FVC Product}

The GEOV1 FVC product (http:/ / land.copernicus.eu/global/products/FCover) that derived from SPOT/VEGETATION data from 1999 to the present is an improvement of CYCLOPES FVC product [25]. The product is provided in a Plate Carrée projection at $1 / 112^{\circ}$ spatial resolution and a 10-day frequency. The GEOV1 FCover product was derived from SPOT/VEGETATION sensor data using back-propagation neural networks. The CYCLOPES FCover product was scaled to train the back-propagation neural networks with the SPOT/VEGETATION top-of-canopy directionally normalized reflectance values over the BELMANIP (Benchmark Land Multisite Analysis and Intercomparison of Products) network of sites [25]. The GEOV1 FVC product corrects the underestimate problem of CYCLOPES FVC product and is closer to the real value [27].

\subsubsection{TRAGL FVC Product}

The TRAGL FVC product was retrieved from GLASS LAI product using physical relations between FVC and LAI [26]. The GLASS LAI product was retrieved using general regression neural networks (GRNNs) from MODIS Version 5 surface reflectance data (MOD09A1)/AVHRR reflectance data [28]. Unlike existing neural network methods that use remote sensing data acquired only at a specific time to retrieve LAI, the GRNNs were trained using fused time series LAI values from MODIS and CYCLOPES LAI products and reprocessed time series MODIS. The temporal and spatial resolution is 8-day and $1 \mathrm{~km}$ with geographic projection. The TRAGL FVC product is spatially and temporally complete. A comparison with GEOV1 FVC product showed that both FVC products were generally consistent in their spatial patterns.

\subsubsection{Li FVC Product}

Li et al. [22] estimated the FVC of northern China from MODIS Version 5 surface reflectance data (MOD09A1) using the dimidiate pixel model, which is one of the most widely used FVC estimation methods $[29,30]$. It assumed that a pixel consisted of only vegetation and non-vegetation components and its value was a linear combination of these two components. If normalized differential vegetation index (NDVI) was used to represent the spectral response, the mathematical expression of the mixed pixel model would be

$$
N D V I=f * N D V I_{v}+(1-f) * N D V I_{S}
$$


then,

$$
f=\frac{N D V I-N D V I_{S}}{N D V I_{v}-N D V I_{S}}
$$

where $f$ was the proportion of vegetation area in the mixed pixel (FVC), NDVI was the NDVI of the mixed pixel, and $N D V I_{v}$ and $N D V I_{S}$ were the $N D V I$ of the fully vegetated and bare soil pixel, respectively. The value of $N D V I_{v}$ and $N D V I_{S}$ was 0.848 and 0.0133 , respectively. The result showed a good performance in the change trend of both inter-annual and within the year. The temporal and spatial resolution is 8 -day and $0.011^{\circ}$ with geographic projection. In the following sections, this data source is called Li FVC.

Because of the inconsistent spatial resolution and projection between the four data sets, the data sets were processed to be spatially matched with geographic projection and the spatial resolution was converted to $0.01^{\circ}$. Then, annual maximum FVC images of four data sets on a pixel-by-pixel basis from 2001 to 2012 were calculated, respectively. In the following sectors, FVC data sets refer to the maximum FVC images of four data sets.

\subsection{Methodology}

\subsubsection{Inter-Annual Change Trend of FVC}

\section{(1) Mann-Kendall Methods}

The Mann-Kendall test [31,32] is a nonparametric method for testing the significance of time series data in hydrological processes and other related physical variables [33-35]. The advantage of this method is that the data does not need to conform to any particular distribution and it has a low sensitivity to abrupt breaks due to the inhomogeneous time series [36]. For a time series, $X=\left\{x_{1}, x_{2}, \cdots, x_{3}\right\}$, the Mann-Kendall test statistic is given as follows:

$$
S=\sum_{i=1}^{n-1} \sum_{j=i+1}^{n} \operatorname{sgn}\left(x_{j}-x_{i}\right)
$$

where $n$ is the number of data points, $x_{i}$ and $x_{j}$ are the data values in time series $i$ and $j(j>i)$, respectively, and $\operatorname{sgn}\left(x_{j}-x_{i}\right)$ is the sign function as follows:

$$
\operatorname{sgn}\left(x_{j}-x_{i}\right)= \begin{cases}1 & x_{j}-x_{i}>0 \\ 0 & x_{j}-x_{i}=0 \\ -1 & x_{j}-x_{i}<0\end{cases}
$$

In cases where the sample size is more than 10 , the standard normal test statistic, $Z$, is computed by:

$$
Z= \begin{cases}\frac{S-1}{\sqrt{\operatorname{Var}(S)}} & S>0 \\ 0 & S=0 \\ \frac{S+1}{\sqrt{\operatorname{Var}(S)}} & S<0\end{cases}
$$

The variance is computed by:

$$
\operatorname{Var}(S)=\frac{n(n+1)(2 n+5)-\sum_{i=1}^{m} t_{i}\left(t_{i}-1\right)\left(2 t_{i}+5\right)}{18}
$$

where $m$ is the number of tied groups and $t_{i}$ denotes the number of ties of extent $i$. A tied group is a set of sample data with the same value. 
Positive values of $Z$ indicate increasing trends while negative $Z$ values show decreasing trends [36]. The trend's significance is assessed by comparing the $Z$ value with the standard normal variance at the pre-specified level of statistical significance [37]. The null hypothesis is rejected and a significant time series trend exists when $|Z|>Z_{1-\alpha / 2} \mid . Z_{1-\alpha / 2}$ is obtained from the standard normal distribution table. In this study, significance levels $\alpha=0.05$ was used which correspond to $Z_{1-\alpha / 2}$ values of 1.960 .

\section{(2) Sen's Slope Estimator}

True slope can be estimated by using a non-parametric method developed by Sen [37] if a linear trend is presented by the Mann-Kendall method. Sen's slope estimator can be computed efficiently and is insensitive to outliers. The slope estimator of $N$ pairs of data are first computed by:

$$
\beta=\operatorname{Median}\left(\frac{x_{j}-x_{i}}{j-i}\right) i=1,2, \cdots N
$$

where $N=n(n-1) / 2$ when there is only one datum in each time period, while $N<n(n-1) / 2$ when there are multiple observations in one or more time periods; where $\mathrm{n}$ is the total number of observations [38]. If $\beta$ is positive that indicates an increase in $X$; if negative, then the $X$ decreases or 0 remains constant.

In this study, the temporal change trends of FVC based on the four FVC products during 2001-2012 were calculated using the Mann-Kendall Method and Sen's slope estimator. The time series $X$ was $F V C_{i}$ which denotes the annual maximum FVC value of the $i$ th year. $n$ is the number of years (equal to 12 in this study) and $i$ represents the year number $(i=1,2,3, \ldots, 12)$.

\subsubsection{Multi-Data FVC Retrieval and Uncertainty Analysis}

A multi-data approach [39] was employed to develop an integrated FVC and reduce the uncertainty from individual data sets. The consistency of each data set was evaluated by computing the correlation and the root-mean-square error (RMSE) of the multi-data set mean, excluding the data set being verified. This method was applied at pixel level to help remove the individual FVC data set with poor data quality from the final averaged FVC. An estimate of the uncertainty in FVC in each year is obtained from the standard error of the mean (SEM):

$$
S E M=s / \sqrt{n}
$$

which depends on the standard deviation $s$ of the $n$ data sets. First, the uncertainty analysis was carried out at the pixel scale. Then, the uncertainty analysis was calculated using the annual mean maximum FVC of the four data sets.

\section{Results}

\subsection{Results of Single FVC Data Sets}

\subsubsection{Spatial Patterns of Each Single FVC Data Set}

Figure 2 shows the spatial patterns of mean annual maximum FVC over the period 2001-2012 in northern China derived from each four data sets respectively. The individual source of FVC values differed in mean amplitude and spatial distribution and the disparity was mainly distributed in Northeast China and North China. Although all the four data sets had the biggest FVC values in Northeast China, the FVC values derived from TRAGL FVC was lower than those of other three data sets by about 0.15 and Li FVC sometimes existed in a saturation phenomenon. Meanwhile, GLASS FVC and TRAGL FVC was almost zero in the southern part of the Xinjiang Uygur autonomous region, the western part of the Inner Mongolia Autonomous Region, and the northwestern part of Ningxia Hui autonomous region; however, FVC values of GEOV1 FVC and Li FVC in those regions were greater 
than zero. This was mainly because Li FVC utilized the dimidiate pixel model in which the choice of $N D V I_{v}$ and $N D V I_{S}$ led to higher values. The GEOV1 FVC product demonstrated that the FVC values were higher than those from SEVIRI in the Validation Report of Land Surface Analysis Vegetation Products (2008). Mu et al. noted that GEOV1 FVC product was generally overestimated for crops by up to 0.20 in the Heihe Basin. GLASS FVC and TRAGL FVC considered the terrestrial ecoregion and land cover type when produced, which made the estimation results more accurate [16].
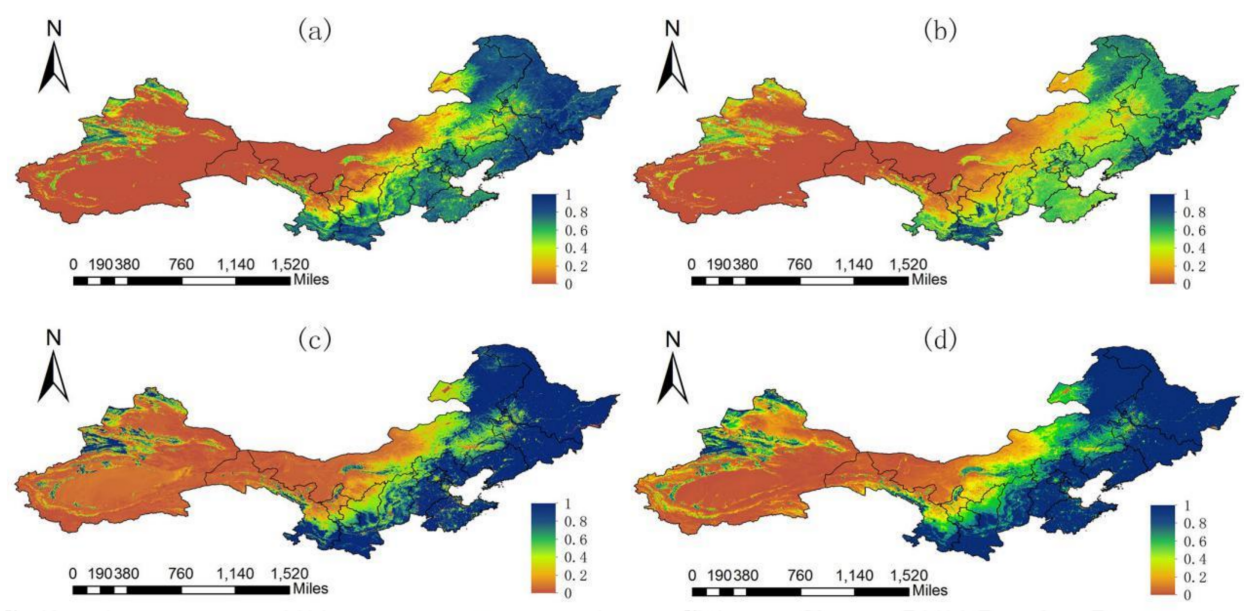

Figure 2. The spatial patterns of maximum FVC over the period 2001-2012 in northern China. (a) GLASS FVC; (b) TRAGL FVC; (c) GEOV1 FVC; (d) Li FVC.

\subsubsection{Variation Trends of Each FVC Data Set}

To evaluate the spatial heterogeneity of FVC change trends, overall linear trends and the linear trends that passed significance level $(p<0.05)$ were calculated at pixel scale shown in Figure 3, respectively. The spatial distribution difference of linear trends was small between the data sets and most of the area had increased in FVC but not significantly. One significant difference among the four data sets was detected in North China, the south part of Xinjiang Uygur autonomous region, the western part of Inner Mongolia Autonomous Region, as well as the northwestern part of Ningxia Hui autonomous region. Of these regions, North China had a significant increase in the four data sets whereas FVC values of the south part of Xinjiang Uygur autonomous region, the western part of Inner Mongolia Autonomous Region, as well as the northwest part of Ningxia Hui autonomous region did not change. Those of GEOV1 FVC showed a significant decrease and those of Li FVC presented a significant increase in some areas of these regions.

Figure 4 shows the inter-annual variations of annual maximum FVC of four data sets in northern China during the period 2001-2012. The mean amplitude, mean variations, and mean variation trend of the four FVC data sets varied among the individual sources. In terms of mean amplitude, the annual mean values of Li FVC were the highest, significantly higher than the other three data sets. This was largely because Li FVC utilizes the dimidiate pixel model in which the choice of $N D V I_{v}$ and $N D V I_{S}$ may lead to overestimates or even saturation. In contrast, those of TRAGL FVC were the lowest and GLASS FVC and GEOV1 FVC were closer to the mean values generated from the four data sets in the study area. As for mean variations and mean variation trends, GEOV1 was significantly higher than the mean values and GLASS FVC was closer to the mean values. Summaries of mean variation trends of FVC estimates over northern China, Northeast China, Northwest China, and North China from the four data sets are shown in Table 2. FVC increased at the rate of $0.26 \%, 0.30 \%, 0.12 \%$, and $0.49 \%$ per year in northern China, North China, Northeast China and Northwest China during the period 2001-2012, respectively. By contrast, GLASS FVC and GEOV1 FVC was closer to the mean values of the four data sets, while the performance of GEOV1 FVC was not better than that of GLASS FVC in terms of mean variations and mean variation trends. 
Table 2. Mean variation trend values of annual average maximum FVC seen by four data sets for 2001-2012.

\begin{tabular}{cccccc}
\hline Region & GLASS FVC & GEOV1 FVC & TRAGL FVC & Li FVC & Average \\
\hline Northern china & 0.0020 & 0.0048 & 0.0016 & 0.0019 & 0.0026 \\
Northeast china & 0.0017 & 0.0072 & 0.0021 & 0.0010 & 0.0030 \\
Northwest china & 0.0012 & 0.0016 & 0.0008 & 0.0013 & 0.0012 \\
North China & 0.0040 & 0.0084 & 0.0029 & 0.0041 & 0.0049 \\
\hline
\end{tabular}
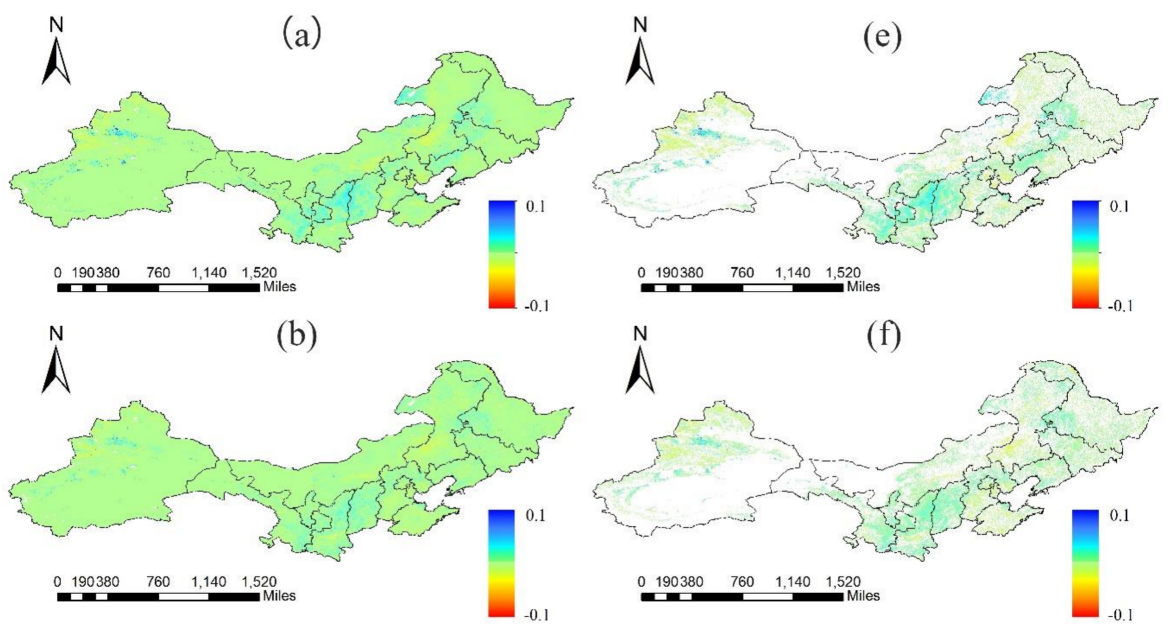

(f)
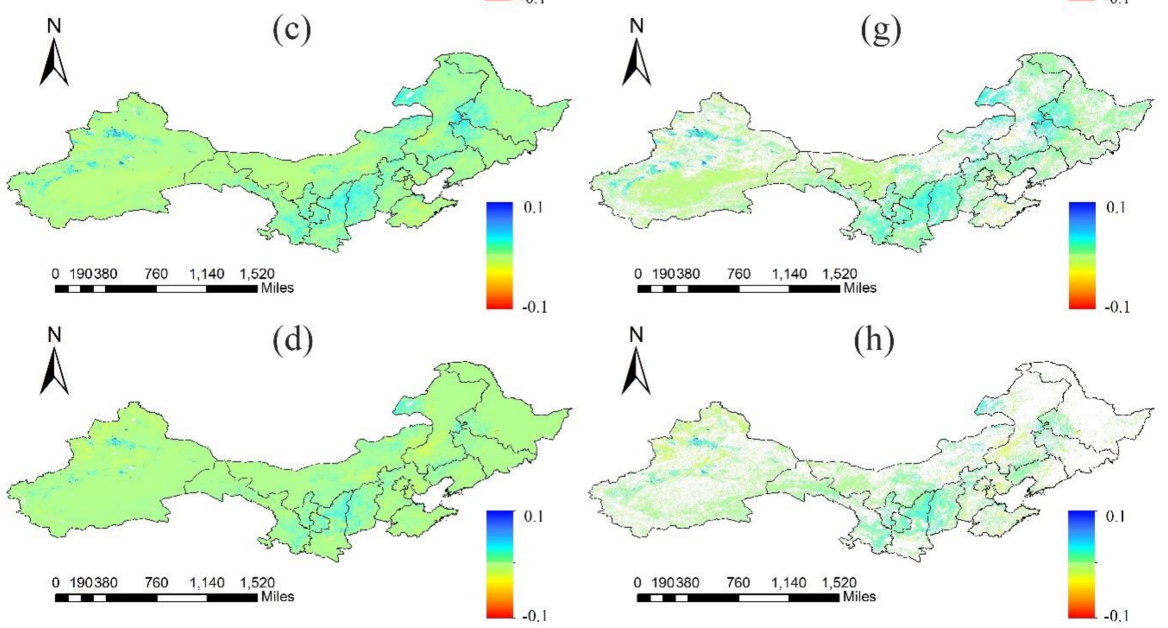

(g)

$\bigwedge^{N}$

(h)

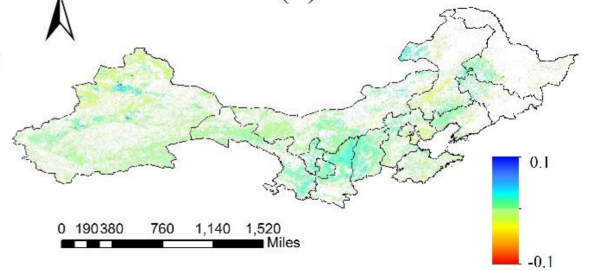

Figure 3. The temporal trends of annual maximum FVC in northern China during the periods 2001-2012. Left column is the temporal trends of (a) GLASS FVC, (b) TRAGL FVC, (c) GEOV1 FVC, (d) Li FVC. Right column is the temporal trends of annual maximum FVC that passed the significant test in northern China during the periods 2001-2012. (e) GLASS FVC; (f) TRAGL FVC; (g) GEOV1 FVC; (h) Li FVC. 

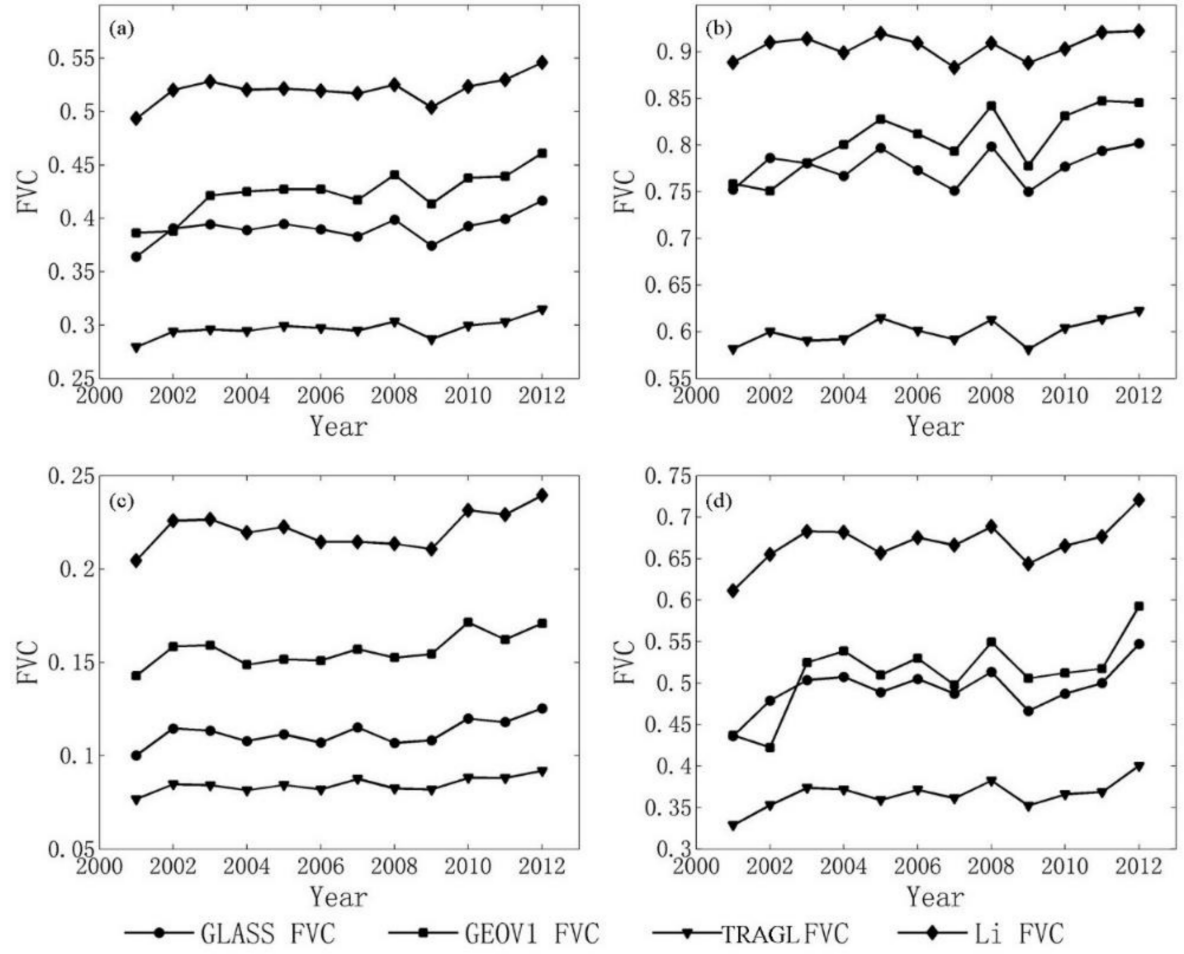

Figure 4. The averages of annual mean maximum FVC of four data sets over the period 2001-2012. (a) northern China; (b) Northeast China; (c) Northwest China; (d) North China.

\subsection{Analysis of Multi-Source FVC Data Set}

\subsubsection{Data Set Evaluation}

The consistency of each data set was evaluated by computing the correlation of coefficient and root mean square error (RMSE) between each data set and averaged FVC from the three other FVC data sets. The evaluation was intended to remove the poorer performing data sets from the average FVC series [39]. This approach was also applied at pixel scale to remove the poorer performing individual FVC data set from the final average data set in each pixel. The correlation and RMSE of each FVC data set and averaged FVC from the three other FVC data sets above the $95 \%$ confidence interval over northern China from 2001 to 2012 are displayed in Figure 5.

The evaluation had been intended to remove the poorer performing data sets from the average FVC series [39]. However, multiple regression analysis revealed that all of the data sets were statistically significant ( 0.05 level) variables in explaining the variance in the multi-data set series. Accordingly, there was no reason to eliminate any of the four data sets. The stratification of the evaluation results revealed that the GLASS FVC had the highest correlation and lowest RMSE compared to the multi-data set average. In contrast, the TRAGL FVC showed higher agreement with other data sets with correlation of a greater coefficient. 

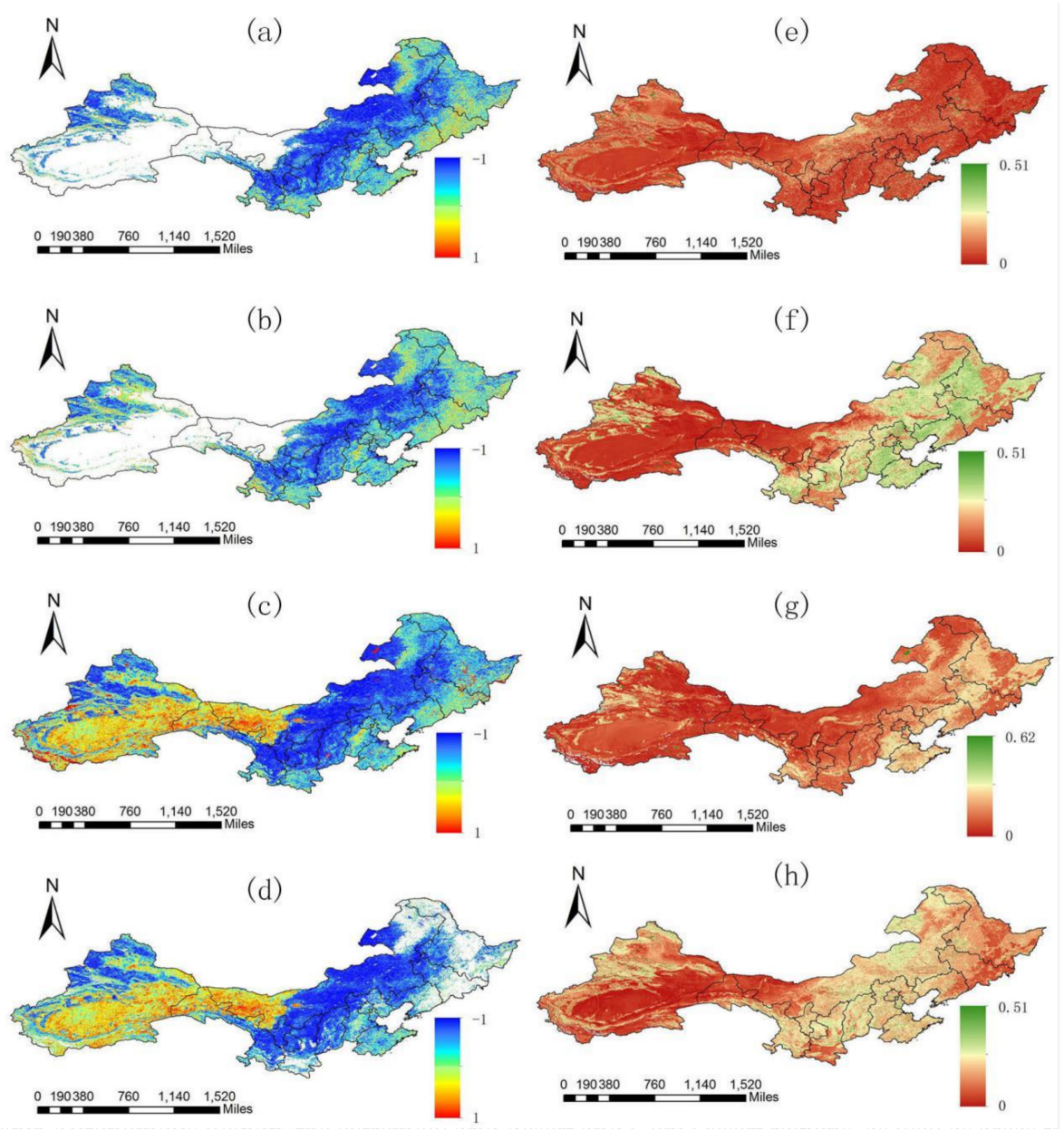

Figure 5. Correlation and root mean square error (RMSE) of each FVC data set with the averaged FVC from the three other FVC data sets used in this study. Left column is the correlation of (a) GLASS FVC, (b) TRAGL FVC, (c) GEOV1 FVC, (d) Li FVC with the average from the other FVC data sets. Right column is the corresponding RMSE value of (e) GLASS FVC, (f) TRAGL FVC, (g) GEOV1 FVC, (h) Li FVC with the average from the other FVC data sets.

\subsubsection{Change Trends of Multi-Source FVC Data Sets}

Figure $6 \mathrm{a}$ shows the slope values calculated from the regression analysis, Figure $6 \mathrm{~b}$ shows the linear trends that passed significance level $(p<0.05)$ by Mann-Kendall test, and Table 3 shows the percentage of significant levels over three parts of northern China. The slope estimate results show that the FVC increased over most areas. Increased regions were mainly distributed in Northeast China and North China. In contrast, the northwestern part of the Xinjiang Uygur Autonomous Region (including Toli, Tacheng, Ili, and Yining counties) and the southern part of the Xinjiang Uygur Autonomous Region, Hulunbeir Plateau, as well as most part of Shandong Province showed various degrees of vegetation decline. 

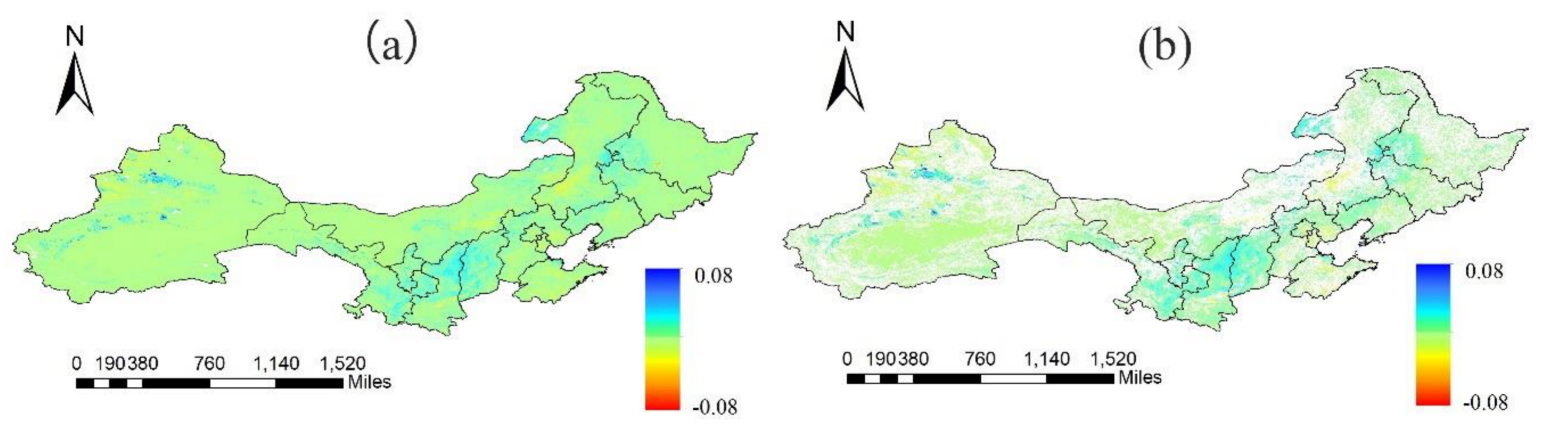

Figure 6. (a) The temporal trends of annual averaged FVC of four data sets in northern China during the period 2001-2012. (b) The temporal trends of annual averaged FVC of four data sets that passed the significant test in northern China during the period 2001-2012.

Table 3. Statistics for the percentage of significant level of FVC change during the period 2001-2012.

\begin{tabular}{cccc}
\hline Regions & Significantly Increased & No Significant Change & Significantly Decreased \\
\hline Northern china & $33.03 \%$ & $50.16 \%$ & $16.81 \%$ \\
Northeast china & $44.88 \%$ & $50.12 \%$ & $5.00 \%$ \\
Northwest china & $23.34 \%$ & $51.86 \%$ & $24.80 \%$ \\
North China & $56.05 \%$ & $35.59 \%$ & $8.36 \%$ \\
\hline
\end{tabular}

In Northeast China, $44.88 \%$ of pixels showed significant increased fractional vegetation cover. $5.00 \%$ of Northeast China showed significant decrease and $50.12 \%$ remained stable. Significant increases were concentrated in the Northeast Plain and the decreased regions were scattered amongst the Daxing' anling Mountains, the Xiaoxing' anling Mountains, and the Changbai Mountains.

In North China, $50.05 \%$ of pixels showed significant increased fractional vegetation cover. $8.36 \%$ of the North China showed a significant decrease in FVC. The areas where vegetation cover declined were mainly distributed in Shandong, Hebei, Tianjin, and Beijing. In $35.59 \%$ of the pixels, the vegetation cover remained stable and had no significant change.

In Northwest China, $23.34 \%$ showed significant increased fractional vegetation cover. Approximately $24.80 \%$ of pixels showed a significant decrease and $51.76 \%$ remained stable. The increases were mainly distributed in the southern Tianshan Mountains and in northern and southern oasis areas. The unchanged regions were mainly distributed in the northwestern part of Xinjiang Uygur Autonomous Region, the extremely arid desert and Gobi Desert regions, as well as areas that are difficult to use and develop. By contrast, an insignificant decrease occurred in the middle parts of the Kunlun Mountains where the climate is very dry.

\subsubsection{Results of Multi-Data FVC and Uncertainty Analysis}

Figure 7a,b shows the spatial distribution of multi-data FVC and uncertainty results generated from the four data sets over northern China during the period 2001-2012, respectively. From the spatial distribution, the FVC values were high over Northeast China while those from Northwest China were almost 0 and those of North China fell in between the two. The uncertainty results of much of Northwest China were almost 0 which indicated low uncertainties. The uncertainty results of North China were around 0.15 while that of Northeast China was about 0.25 . In general, in contrast to the low FVC area, the high FVC area of northern China had a high degree of uncertainty. 

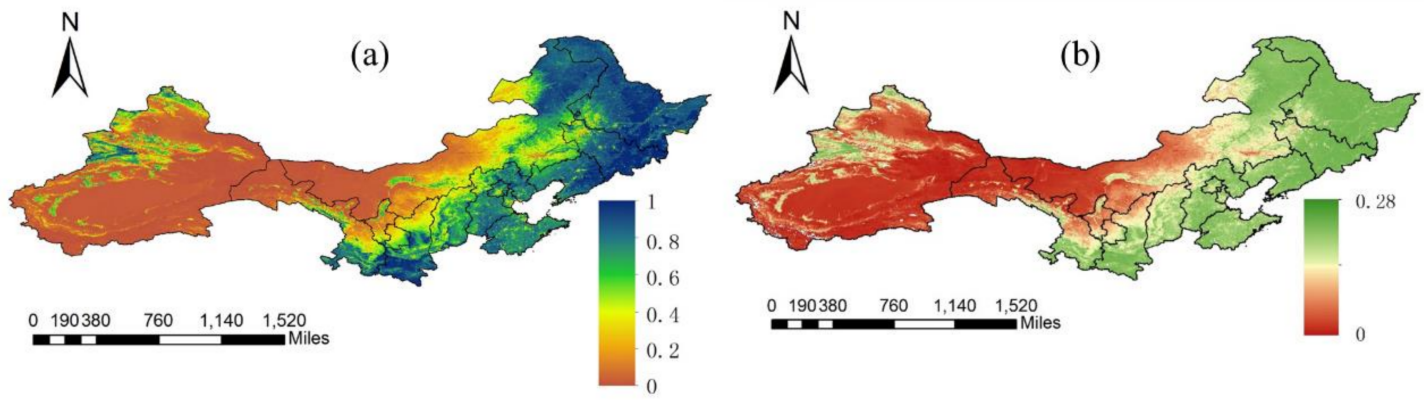

Figure 7. Spatial pattern of mean maximum FVC (a) and standard error (b) of multi-data sets over the northern China during the period 2001-2012.

Annual-averaged maximum FVC from 2001 to 2012 with error bars (standard error) generated from multi-data sets over northern China, Northeast China, Northwest China, and North China during the period 2001-2012, is shown in Figure 8, respectively. The multi-data set shows a significant increase in FVC over northern China from 2001 to 2012 and the estimates show a more linear increase in FVC than the previous single data set. Low FVC can be seen in 2001 and 2009, especially in Northeast China. 2001 was a year of extreme drought and the precipitation was lower than normal in most regions of northern China [40]. Different degrees of drought occurred in all seasons. In 2009, low temperatures, snowfall in winter, as well as drought in spring and autumn [41] inhibited vegetation growth in this region, causing the annual mean FVC to decrease.
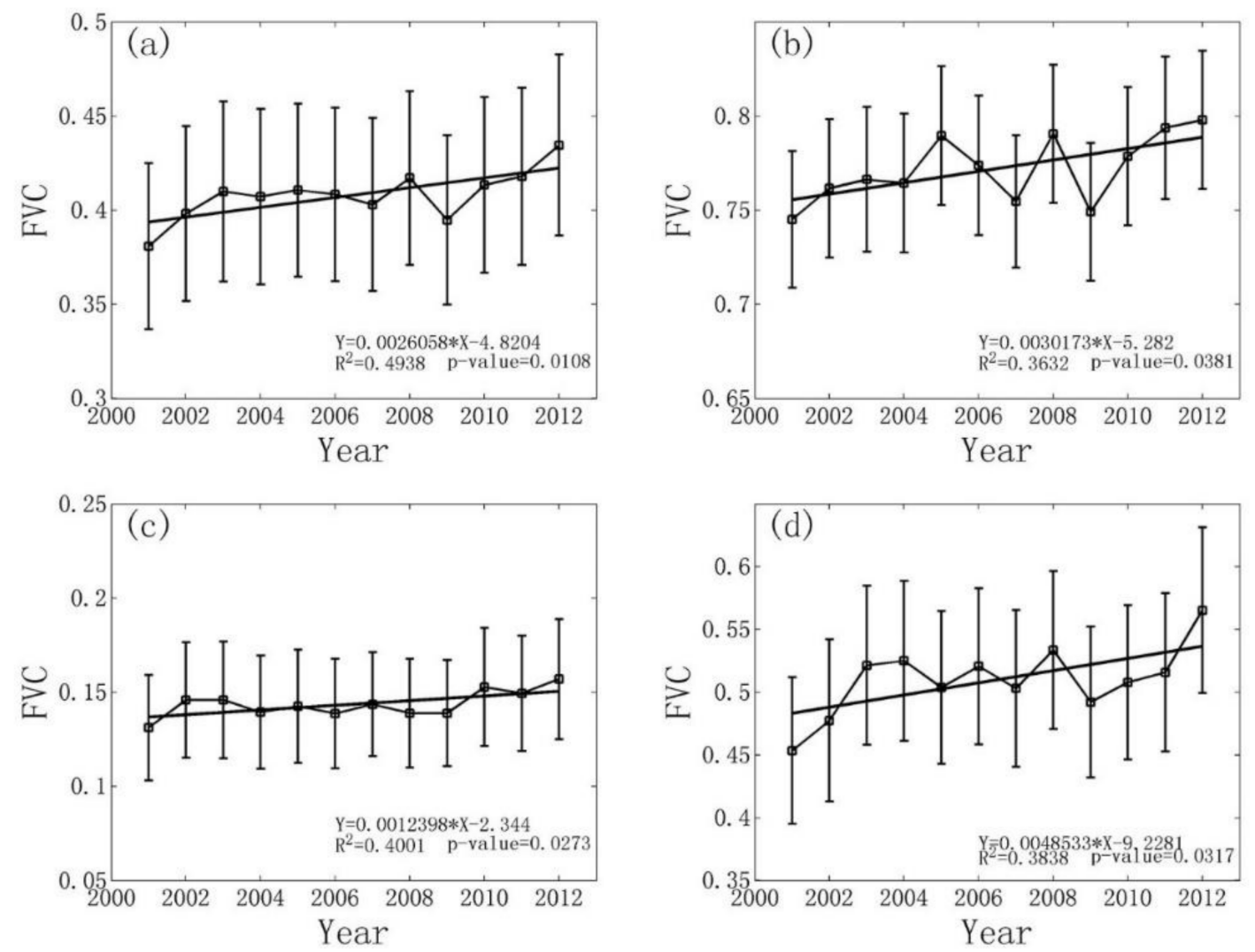

Figure 8. The averages of annual mean maximum FVC and trend in FVC with the error bars showing the standard error of multi-data set average. (a) northern China; (b) Northeast China; (c) Northwest China; (d) North China. 
From the regional scale, the FVC over Northeast China significantly increased at a rate of $0.3 \%$ /year from 2001 to $2012\left(R^{2}=0.3632, p\right.$-value $\left.=0.0381\right)$. Similarly, Northwest China had a significant increase at the rate of $0.12 \%$ /year in FVC from 2001 to $2012\left(R^{2}=0.4001, p\right.$-value $\left.=0.0273\right)$. In general, the growth trend was relatively flat. The FVC over North China significantly increased at a rate of $0.49 \%$ /year during the period 2001-2012. Similarly, North China underwent an intense and prolonged drought episode in 2009.

Comparing the three parts, North China had a more obvious increasing trend, while that of Northeast and Northwest China was not so significant. In all of northern China, 33.03\% of pixels showed significant increase fractional vegetation cover, approximately $16.81 \%$ of pixels showed significant decrease, and $50.16 \%$ remained stable. In general, vegetation in northern China has increased during the period 2001-2012.

\section{Discussions}

The FVC dynamics from 2001-2012 in northern China has been analyzed from four satellite data products in this study. We found a more linear increase in FVC than did previous studies using a single data set. The four data sets show a consistent agreement. The spatial patterns of temporal trends of annual mean are similar among the data sets; however, the GEOV1 FVC product shows relatively bigger variations in trend. From the points of temporal trends and inter-annual variability of annual mean FVC, the GLASS FVC is closer to the mean values of the four data sets.

To date, analysis of vegetation cover change over northern China has relied on single sources of information that can be affected by both estimation methods and satellite sensors. The multi-data set approach taken in this study can reduce the impact of inconsistencies and provide a more reliable estimate of the uncertainty of FVC in each year. Trend analysis of the multi-data set (including an annually varying estimate of error) reveals that FVC has increased at a rate of $0.26 \pm 0.13 \%$, $0.30 \pm 0.25 \%, 0.12 \pm 0.03 \%, 0.49 \pm 0.21 \%$ per year in northern China, Northeast China, Northwest China, and North China during the period 2001-2012, respectively. Most areas of northern China have increased in vegetation, especially in the Northeast Plain, the central part of North China, and the Hulunbuir prairie. In all of northern China, $33.03 \%$ of pixels showed significantly increased fractional vegetation cover, approximately $16.81 \%$ of pixels showed significant decrease, and $50.16 \%$ remained stable. Meanwhile, North China had a more obvious increasing trend while that of Northeast and Northwest China was not so significant.

In this study, the multi-data FVC was retrieved from four FVC data set from 2000 to 2012. However, the ecological programs were implemented in the 1980s. Therefore, the method which considered different FVC data sets can be used to provide a long-term multi-data set analysis. For example, the GEOV1 FVC can be obtained from 1982 to the present while the GLASS FVC, which provided the FVC estimates from 1982 to 2016, is going to be released in the near future. In addition, other land surface products, such as tree cover products and land use products, can also be used to provide evidence about the condition of vegetation change in northern China.

\section{Conclusions}

This study conducted a spatio-temporal analysis of fractional vegetation cover change in northern China during 2001-2012 based on multiple data sets. Results indicated that fractional vegetation cover increased in northern China from 2000 to 2012 but not significantly. In addition, this study also provides an estimate of uncertainty in FVC at pixel and regional scale. However, this study, which covered the period from 2000 to 2012, is limited in its ability to provide direct evidence for the effects of ecological programs on vegetation change of northern China since the ecological programs were implemented in the 1980s. Although the methodology used in this study was not inherently complex, it is very effective and has been used in many related studies and can be used for large areas or even globally. Further work will focus on the evaluation of vegetation changes by using more land surface products, such as land cover type data and/or tree cover data. 
Acknowledgments: This study was partially supported by the National Key Research and Development Program of China (NO. 2016YFA0600103) and the National Natural Science Foundation of China (No. 41671332).

Author Contributions: L.Y., K.J. and S.L. conceived and designed the experiments; L.Y. performed the experiments; K.J. and L.Y. conducted the analysis of the results; and all of the authors contributed towards writing the manuscript.

Conflicts of Interest: The authors declare no conflict of interest.

\section{References}

1. Cao, S. Why Large-Scale Afforestation Efforts in China Have Failed To Solve the Desertification Problem. Environ. Sci. Technol. 2008, 42, 1826-1831. [CrossRef] [PubMed]

2. Brown, L.R.; Halweil, B. China's water shortage could shake world food security. World Watch 1998, 11, 10-16. [PubMed]

3. Zhai, P.; Chao, Q.; Zou, X. Progress in China's climate change study in the 20th century. J. Geogr. Sci. 2004, 14, 3-11.

4. Wang, W.; Shao, Q.; Peng, S.; Zhang, Z.; Xing, W.; An, G.; Yong, B. Spatial and temporal characteristics of changes in precipitation during 1957-2007 in the Haihe River basin, China. Stoch. Environ. Res. Risk Assess. 2011, 25, 881-895. [CrossRef]

5. Bonan, G.B. Forests and climate change: Forcings, feedbacks, and the climate benefits of forests. Science 2008, 320, 1444-1449. [CrossRef] [PubMed]

6. Jiang, B.; Liang, S.; Yuan, W. Observational evidence for impacts of vegetation change on local surface climate over northern China using the Granger causality test. J. Geophys. Res. Biogeosci. 2015, 120, 1-12. [CrossRef]

7. Anderson, R.G.; Canadell, J.G.; Randerson, J.T.; Jackson, R.B.; Hungate, B.A.; Baldocchi, D.D.; Ban-Weiss, G.A.; Bonan, G.B.; Caldeira, K.; Cao, L.; et al. Biophysical considerations in forestry for climate protection. Front. Ecol. Environ. 2011, 9, 174-182. [CrossRef]

8. Duan, H.; Yan, C.; Tsunekawa, A.; Song, X.; Li, S.; Xie, J. Assessing vegetation dynamics in the Three-North Shelter Forest region of China using AVHRR NDVI data. Environ. Earth Sci. 2011, 64, 1011-1020. [CrossRef]

9. Yin, R.; Rothstein, D.; Qi, J.; Liu, S. Methodology for an Integrative Assessment of China's Ecological Restoration Programs. In An Integrated Assessment of China's Ecological Restoration Programs; Springer: Dordrecht, The Netherlands, 2009; pp. 39-54.

10. Uchida, E.; Xu, J.; Rozelle, S. Grain for Green: Cost-Effectiveness and Sustainability of China's Conservation Set-Aside Program. Land Econ. 2005, 81, 247-264. [CrossRef]

11. Pimentel, D.; Harvey, C.; Resosudarmo, P.; Sinclair, K.; Kurz, D.; McNair, M.; Crist, S.; Shpritz, L.; Fitton, L.; Saffouri, R.; et al. Environmental and economic costs of soil erosion and conservation benefits. Science 1995, 267, 1117-1123. [CrossRef] [PubMed]

12. Jacinthe, P.A.; Lal, R. A mass balance approach to assess carbon dioxide evolution during erosional events. Land Degrad. Dev. 2001, 12, 329-339. [CrossRef]

13. Wu, Y.; Zeng, Y.; Wu, B.; Li, X.; Wu, W.B. Retrieval and analysis of vegetation cover in the Three-North Regions of China based on MODIS data. Chin. J. Ecol. 2009, 28, 1712-1718.

14. Dong, L.S.; Bo, Z.H. The Comparison Study on Forestry Ecological Projects in the World. Acta Ecol. Sin. 2002, 22, 1976-1982.

15. Liang, S.; Li, X.; Wang, J. Advanced Remote Sensing: Terrestrial Information Extraction and Applications; Academic Press: Oxford, UK, 2012; p. 800.

16. Jia, K.; Liang, S.; Liu, S.; Li, Y.; Xiao, Z.; Yao, Y.; Jiang, B.; Zhao, X.; Wang, X.; Xu, S.; et al. Global Land Surface Fractional Vegetation Cover Estimation Using General Regression Neural Networks From MODIS Surface Reflectance. IEEE Trans. Geosci. Remote Sens. 2015, 53, 4787-4796. [CrossRef]

17. Jia, K.; Liang, S.; Wei, X.; Li, Q.; Du, X.; Jiang, B.; Yao, Y.; Zhao, X.; Li, Y. Fractional Forest Cover Changes in Northeast China From 1982 to 2011 and Its Relationship With Climatic Variations. IEEE J. Sel. Top. Appl. Earth Obs. Remote Sens. 2015, 8, 775-783. [CrossRef]

18. Yang, L.; Jia, K.; Liang, S.; Liu, J.; Wang, X. Comparison of Four Machine Learning Methods for Generating the GLASS Fractional Vegetation Cover Product from MODIS Data. Remote Sens. 2016, 8, 682. [CrossRef]

19. Su, W.; Yu, D.-Y.; Sun, Z.-P.; Zhan, J.-G.; Liu, X.-X.; Luo, Q. Vegetation changes in the agricultural-pastoral areas of northern China from 2001 to 2013. J. Integr. Agric. 2016, 15, 1145-1156. [CrossRef] 
20. Liu, S.; Wang, T.; Guo, J.; Qu, J.; An, P. Vegetation change based on SPOT-VGT data from 1998 to 2007, northern China. Environ. Earth Sci. 2009, 60, 1459-1466. [CrossRef]

21. Zhang, R.; Feng, Q.; Guo, J.; Shang, Z.; Liang, T. Spatio-temporal Changes of NDVI and Climatic Factors of Grassland in Northern China from 2000 to 2012. J. Desert Res. 2015, 35, 1403-1412.

22. Li, Y.; Jia, K.; Wei, X.; Yao, Y.; Sun, J.; Mou, L. Fractional vegetation cover estimation in northern China and its change analysis. Remote Sens. Land Resour. 2015, 27, 112-117.

23. Li, Y.; Sulla-Menashe, D.; Motesharrei, S.; Song, X.P.; Kalnay, E.; Ying, Q.; Li, S.; Ma, Z. Inconsistent estimates of forest cover change in China between 2000 and 2013 from multiple datasets: Differences in parameters, spatial resolution, and definitions. Sci. Rep. 2017, 7, 8748. [CrossRef] [PubMed]

24. Wang, X.; Fang, J.; Tang, Z.; Zhu, B. Climatic control of primary forest structure and DBH-height allometry in Northeast China. For. Ecol. Manag. 2006, 234, 264-274. [CrossRef]

25. Baret, F.; Weiss, M.; Lacaze, R.; Camacho, F.; Makhmara, H.; Pacholcyzk, P.; Smets, B. GEOV1: LAI and FAPAR essential climate variables and FCOVER global time series capitalizing over existing products. Part1: Principles of development and production. Remote Sens. Environ. 2013, 137, 299-309. [CrossRef]

26. Xiao, Z.; Wang, T.; Liang, S.; Sun, R. Estimating the Fractional Vegetation Cover from GLASS Leaf Area Index Product. Remote Sens. 2016, 8, 337. [CrossRef]

27. Camacho, F.; Cernicharo, J.; Lacaze, R.; Baret, F.; Weiss, M. GEOV1: LAI, FAPAR essential climate variables and FCOVER global time series capitalizing over existing products. Part 2: Validation and intercomparison with reference products. Remote Sens. Environ. 2013, 137, 310-329. [CrossRef]

28. Xiao, Z.; Liang, S.; Wang, J.; Chen, P.; Yin, X.; Zhang, L.; Song, J. Use of General Regression Neural Networks for Generating the GLASS Leaf Area Index Product From Time-Series MODIS Surface Reflectance. IEEE Trans. Geosci. Remote Sens. 2014, 52, 209-223. [CrossRef]

29. Gutman, G.; Ignatov, A. The derivation of the green vegetation fraction from NOAA/AVHRR data for use in numerical weather prediction models. Int. J. Remote Sens. 1998, 19, 1533-1543. [CrossRef]

30. Qi, J. Spatial and temporal dynamics of vegetation in the San Pedro River basin area. Agric. For. Meteorol. 2000, 105, 55-68. [CrossRef]

31. Mann, H.B. Nonparametric Tests against Trend. Econometrica 1945, 13, 245. [CrossRef]

32. Forthofer, R.N.; Lehnen, R.G. Rank Correlation Methods; Springer: New York, NY, USA, 1981; pp. $146-163$.

33. Zhao, X.; Tan, K.; Zhao, S.; Fang, J. Changing climate affects vegetation growth in the arid region of the northwestern China. J. Arid Environ. 2011, 75, 946-952. [CrossRef]

34. Tabari, H.; Marofi, S. Changes of Pan Evaporation in the West of Iran. Water Resour. Manag. 2010, 25, 97-111. [CrossRef]

35. Hamed, K.H. Exact distribution of the Mann-Kendall trend test statistic for persistent data. J. Hydrol. 2009, 365, 86-94. [CrossRef]

36. Jaagus, J. Climatic changes in Estonia during the second half of the 20th century in relationship with changes in large-scale atmospheric circulation. Theor. Appl. Climatol. 2005, 83, 77-88. [CrossRef]

37. Sen, P.K. Estimates of the Regression Coefficient Based on Kendall's Tau. J. Am. Stat. Assoc. 1968, 63, 1379-1389. [CrossRef]

38. Tabari, H.; Hosseinzadeh Talaee, P. Analysis of trends in temperature data in arid and semi-arid regions of Iran. Glob. Planet. Chang. 2011, 79, 1-10. [CrossRef]

39. Brown, R.; Derksen, C.; Wang, L. A multi-data set analysis of variability and change in Arctic spring snow cover extent, 1967-2008. J. Geophys. Res. 2010, 115. [CrossRef]

40. Lu, J. Features of Weather/Climate over China in 2001. Meteorol. Mon. 2002, 29, 32-36.

41. Chen, H.; Fan, X. Some Extreme Events of Weather, Climate and Related Phenomena in 2009. Clim. Environ. Res. 2010, 15, 322-336.

(C) 2018 by the authors. Licensee MDPI, Basel, Switzerland. This article is an open access article distributed under the terms and conditions of the Creative Commons Attribution (CC BY) license (http:/ / creativecommons.org/licenses/by/4.0/). 